\title{
Constitución de 1949. Una mirada desde un enfoque de género
}

Natalia Sereno $^{1}$ | Universidad Nacional de Tres de Febrero

Revista Derechos en Acción ISSN 2525-1678/ e-ISSN 2525-1686

Año 4/Nº 11 Otoño 2019 (21 marzo a 21 junio), 687-707

DOI: https://doi.org/10.24215/25251678e297

\section{Introducción}

En 1949, en Argentina se realiza una reforma constitucional promovida durante el primer gobierno de Juan Domingo Perón. Esta constitución, que es muy novedosa en cuestiones de derechos sociales, políticos y económicos. Particularmente, esta constitución introduce modificaciones sustanciales en torno a la propiedad, la economía y la soberanía. Esta es una constitución enmarcada en la corriente del constitucionalismo social.

Desde un enfoque de género, si bien pretende se novedosa y estar alineada con un clima de época, por sus mismas valoraciones implícitas, subroga el lugar de la mujer aún no tenemos una idea de género tal como en estos tiempos) a un lugar funcional al bien jurídico protegido de interés, que es la familia, estructurado desde la Carta Magna, desigualdades de género.

Desde una revisión crítica de este posicionamiento legislativo podemos ver como desde una visión legislativa ligada a la moral y costumbres heteropatriacales de contexto histórico argentino, se genera un cuerpo legislativo que, por individualizar posicionamientos específicos hacia la mujer, ligados a estereotipos y roles sociales, se tipifican situaciones que vulneran los derechos de las mismas en vez de proteger sus mejores intereses.

1 Abogada especializada en Género e Investigadora de la Universidad Nacional Tres de Febrero, integrante de la Constituyente Feminista. 
Esta Constitución fue sancionada en el marco de una voluntad política revolucionaria en el marco de la introducción un espíritu que el mismo Perón expresa en un discurso en 1948: "la revolución peronista ha iniciado una nueva etapa en lo político, en lo social y en lo económico", intentando influir la voluntad de reforma constitucional acorde a los lineamientos políticos de su gobierno.

Los planteos de Arturo Enrique Sampay, abogado de la Universidad Nacional de la Plata (1932), miembro de la Comisión Revisora de la Constitución, orientaron el enfoque político de la reforma que es fuertemente social y nacionalista. La idea era dar un enfoque constitucional a la obra política del peronismo, observando que la constitución de 1853, expresión de la oligarquía el país, elitista y de tendencias aristocráticas, obstaculizaba que el Argentina se diera una verdadera democracia de masas.

En lo económico, las modificaciones tuvieron que ver con la introducción de un esquema acorde al modelo industrialista de 1943, basándose en el fracaso de políticas liberales anteriores, buscando esquemas nacionales y que la constitución no se constituyera como una copia de modelos extranjeros.

En lo social, los modelos se vieron influenciados fuertemente por ideas religiosas, de allí tenemos la importancia que dedica al modelo de familia hegemónico para la época; también por los principios del bien común y el uso social de las riquezas que propugnaba la iglesia en sus encíclicas.

\section{Derechos Sociales}

En lo relativo a los derechos sociales aparecen los derechos del trabajador, de la familia, de la ancianidad, la educación y la cultura, como ideal del nuevo modelo de democracia y del ideal de justicia social, que vamos a retomar luego desde una perspectiva de género.

Las primeras observaciones pueden realizarse en torno a las modificaciones en el preámbulo, el cuál manifestaría: 
"...la irrevocable decisión de constituir una Nación socialmente justa, económicamente libre y políticamente soberana."

Si bien el Preámbulo de la Constitución de la Nación Argentina no tiene carácter normativo, siempre se lo ha considerado como un programa político.

El agregado está relacionado con el reconocimiento de tres nuevos principios básicos para la Nación:

"Socialmente justa»: se refiere al reconocimiento de la justicia social.

"Económicamente libre»: hace referencia a la idea de independencia económica e indirectamente a los mecanismos de dependencia neocolonial.

"Políticamente soberana»: se refiere al concepto clásico de independencia política fortalecido con la noción moderna del derecho de autodeterminación de los pueblos.

Por otra parte, tomado la Constitución del 49, en el capítulo III, titulado "Derechos del trabajador, de la familia, de la ancianidad y de la educación y la cultura", tiene un solo y extenso artículo, el artículo dividido a su vez en cuatro secciones, para especificar los derechos...:

- del trabajo.

- de la familia.

- de la ancianidad.

- de la educación y la cultura.

La segunda sección del artículo 37, dedicada a los derechos de la familia, declaró "la igualdad jurídica del hombre y la mujer en el matrimonio y la patria potestad, garantizó el bien de familia que protegía la vivienda única de los juicios por deudas, y estableció una protección especial para la maternidad y la infancia."

Así enuncia la Constitución de 1949

"CAPITULO III

Derechos del trabajador, de la familia, de la ancianidad $y$ de la educación y la cultura 
Art. 37.- Declaranse los siguientes derechos especiales:

(..)

1 - Estado protege el matrimonio, garantiza la igualdad jurídica de los cónyuges y la patria potestad;

2. - El Estado formara la unidad económica familiar, de conformidad con lo que una

ley especial establezca;

3. - El Estado garantiza el bien de familia conforme a lo que una ley especial determine;

4.- La atencion y asistencia de la madre y del niño gozarán de la especial y privilegiada consideraci6n del Estado.

(...)

8. - Derecho a la protección de su familia. - La protección de la familia responde a un natural designio del individuo, desde que en ella generan sus más elevados sentimientos afectivos, $y$ todo empeño tendiente a su bienestar debe ser estimulado y favorecido por la comunidad, como el medio más indicado de pro pender al mejoramiento del género bumano y a la consolidación de principios espirituales y morales que constituyen la esencia de la convivencia social."

Como podemos observar, las posiciones de los derechos de la mujer quedaban ligados a un concepto de familia héteropatriarcal, no inclusivo de otras realidades existentes. El bien jurídico protegido en juego era el de la familia de acuerdo a un orden normativo establecido con el ordenamiento de género, como si estos estuviesen determinados en la naturaleza humana. Se pone en juego la existencia de un derecho natural en torno a un ideal de familia.

Por lo tanto, el posicionamiento de las mujeres queda ligado a un posicionamiento familiar orgánico a las políticas reproductivas y de división del trabajo. 


\section{Reclamos feministas en el mundo}

Mientras se sancionaba Constitución de 1949, el mundo asiste a reclamos feministas en una segunda etapa o pertenecientes a lo que se llamó segunda ola. Esta etapa se caracterizó y fue denominada como etapa sufragista

En tal sentido, el sufragismo tenía dos objetivos: el derecho al voto y los derechos educativos. Ambos marcharon a la par apoyándose mutuamente. El costoso acceso a la educación tenía relación directa con los derechos políticos ya que a medida que la formación de algunas mujeres avanzaba, se hacía más difícil negar el derecho al voto. El movimiento sufragista era de carácter interclasista ya que consideraban que todas las mujeres sufrían en cuanto mujeres, independientemente de su clase social, discriminaciones semejantes.

El centro del debate feminista la consecución del derecho de voto para la mujer: la solución de la cuestión femenina pasaba por la eliminación de toda traba legislativa discriminatoria. Una vez suprimida estas restricciones, las mujeres superarían su subordinación y lograrían su emancipación.

Hacia los años 30 la mayoría de las naciones desarrolladas habían reconocido el derecho al voto femenino. Las feministas de esta primera época plantearon también el derecho al libre acceso a los estudios superiores y a todas las profesiones, la igualdad de derechos civiles, compartir la patria potestad de los hijos, denunciaban que el marido fuera el administrador de los bienes conyugales, pedían igual salario para igual trabajo. Todos estos objetivos se centraron en el derecho al voto, que parecía la llave para conseguir los demás. Las feministas del siglo XIX y principios del XX pusieron énfasis en los aspectos igualitarios y en el respeto a los valores democráticos. Era un movimiento basado en los principios liberales.

Con el advenimiento de la Segunda Guerra Mundial, las mujeres toman espacios tradicionalmente ocupados por hombres, ocupando puestos de trabajo, jefaturas en el seno de sus 
familias, la mujer cobra una autonomía que no va a durar más allá de los que le es de utilidad al orden patriarcal y por un momento determinado, el de duración de la guerra.

Tras la Segunda Guerra Mundial, los gobiernos y los medios de comunicación de masas se comprometieron en un doble objetivo: alejar a las mujeres de los empleos obtenidos durante el periodo bélico devolviéndolas al hogar y diversificar la producción fabril, recurriendo a la implantación cultural del valor de "la mística de la feminidad". Las mujeres debían encontrar en el papel de ama de casa un destino confortable y no salir a competir al mercado laboral. Pero esta "mística de lo femenino" estaba produciendo graves trastornos en la población femenina sobre la que se ejercía.

Inmediatamente antes de esta maniobra, se había producido una obra fundamental para el feminismo, El segundo sexo de Simone de Beauvoir (1949): Simone de Beauvoir analiza a las mujeres como el otro, el sexo femenino es la otra cara del espejo de la evolución del mundo masculino y aporta un análisis no biologicista al afirmar "no se nace mujer, se llega a serlo". La libertad es la idea central de esta obra que, sin embargo, cayó en el vacío pues se produjo en el mismo momento en que la mística de la feminidad se estaba forjando.

\section{Volviendo a Argentina}

Desde esta perspectiva y acompañando el clima de época, la Constitución del 49, lejos de ser revolucionaria en derechos de género, y de forjar bases para la igualdad jurídica entre mujeres y hombres, legitima estereotipos que, por sus prácticas vinculantes y situaciones estructurales no reconocidas por el Estado, son impulsoras de desigualdades de género.

Podemos decir ya que no hay justicia social, libertad económica y soberanía política, sin que el estado establezca bases para una real igualdad de género, equiparando bases en todas las áreas para que las mujeres y otras realidades de género tengamos reales oportunidades igualitarias. 


\section{Reforma de 1994 y derechos de género}

En la Reforma Constitucional de 1994, la introducción de cláusulas que reconocieran los derechos de las mujeres en la Constitución fue una preocupación compartida por el Consejo Nacional de las Mujeres, mujeres representantes de los partidos políticos, legisladoras, académicas y juristas, desde mucho tiempo antes que el Congreso Nacional sancionara la ley que declaraba la necesidad de la reforma. De cara al nuevo derecho internacional y al reconocimiento de los derechos humanos en las modernas constituciones, se apoyó la propuesta para que se considerara la jerarquización dentro del ordenamiento jurídico argentino, de los tratados y convenciones internacionales sobre derechos humanos.

El Consejo Nacional de las Mujeres convocó a la Comisión de Mujeres Representantes de los Partidos Políticos a efectos de acordar una serie de actividades a realizar en relación a este tema. Se consensuaron propuestas comunes en base a las presentadas por el Consejo y las mujeres de los distintos partidos políticos, se elaboró una estrategia de trabajo con las/ los Constituyentes.

La Reforma Constitucional de 1994 ha significado un importante avance cualitativo en el reconocimiento de los derechos de las mujeres, ya que ha asignado a la Convención sobre la Eliminación de todas las Formas de Discriminación contra la Mujer la mayor jerarquía en la pirámide legal. En el artículo 75 inc. 22 de la Constitución Nacional se menciona que todos los tratados de derechos humanos allí incorporados tienen jerarquía constitucional, dejando abierta la posibilidad de que se incorporen otros instrumentos de derechos humanos, mediando aprobación por mayorías especiales en el Congreso Nacional.

Si bien esto ocurre, tenemos que tener en cuenta que estos derechos se incorporan como derechos programáticos, encomendando su regulación al legislador u otra autoridad de la república para que recién allí sea posible que los jueces puedan aplicar estas normas. Al no contener operatividad, necesitan de otras normas para adquirir exigibilidad. 
Allí nos encontramos con una traba fundamental para exigir derechos de género que, si bien quedaron enunciados en la Constitución, no podemos exigirlos sin norma que los haga operativos y en otro orden, que reglamente su operatividad, quedando entrampados en el funcionamiento del derecho y de un Estado invisibilizado en sus obligaciones de cumplimiento, un estado que omite en el decurso del tiempo, poner en funcionamiento la articulación normativa necesaria para hacerse cargo de sus responsabilidades que debieran ser inmediatas.

La ilusión del derecho a la igualdad como punto de partida

Puede resultar casi un lugar común denunciar que las mujeres somos víctimas de toda clase de violencias. Estas violencias atraviesan ámbitos públicos y privados, se retroalimentan en ámbitos variados: desde los enmascarados posicionamientos en el terreno afectivo tributario del modelo de amor romántico, las organizaciones domésticas, las exigencias objetualizantes de la estética, la división sexual del trabajo o el estrecho accionar judicial que involucra a operadores y a decisiones judiciales moldeadas por el mismo orden. Puede resultar un lugar común, una protesta recurrente, un enunciado remanido, y en esa posibilidad se esconde una operación invisibilizante de una verdad: la supuesta igualdad entre mujeres y hombres, no existe.

A pesar de las luchas de los feminismos por reivindicar los derechos de las mujeres, todavía estamos en un estado temprano del proceso por equiparar desigualdades estructurales. Las desigualdades en el terreno laboral, la violencia en ámbitos domésticos, la violencia sexual, violencia obstétrica, violencia psicológica hacia las mujeres apuntan a domesticar cuerpos para que el avance de las reivindicaciones y los reclamos por igualdad y justicia no sean posibles. Y estos términos exceden la lógica del patriarcado: no es posible la vida comunitaria si persiste la injusticia social.

La ilusión de la supuesta "igualdad conquistada" no es más que una represa para desalentar reclamos, para compeler sujetos a la normativa ya establecida. 
En el capitalismo hétero-patriarcal, en términos de paradigma, como sujetos de producción, no solo nos vemos compelidos a la producción de bienes y servicios. También producimos verdad. En este sentido, el patriarcado ha desarrollado su estrategia más poderosa: no solo en el sentido de producir verdad. El sistema patriarcal produce interpretaciones, condicionamientos de la realidad y, por lo tanto, significa.

Dado el modo de producir verdad del patriarcado, hablar de igualdades conquistadas y ya establecidas es un modo de invisibilizar que la tarea de transformar la sociedad en un sistema justo y equitativo recién comienza y que todavía no existen situaciones fácticas de igualdad en ningún ámbito social, salvo en una dimensión enunciativa.

El orden judicial no es una excepción a esta regla. Mientras que se generan leyes de abordaje de situaciones de violencia contra las mujeres y protocolos institucionales para tratar y abordar casos puntuales de violencia, no existe un tratamiento de género efectivo en la justicia, ni en sus procedimientos, ni en la capacitación regulada de sus operadores, ni en las decisiones de las jueces teñidas de valoraciones opresivas hacia las mujeres.

Esta desinteligencia o falta de voluntad política para el tratamiento de la problemática no arroja otro resultado que el de mujeres sometidas, excluidas, golpeadas, violadas, encerradas, muertas: mujeres desarticuladas.

Existen políticas detrás de la ausencia de legalidad como también detrás de las medidas de protección. En el caso específico de las mujeres, las medidas de protección suelen estar ligadas a la política de control.

Si bien los sectores de la población ligados a la pobreza son aquellos más padecientes de estas políticas, dado su grado de vulneración, en el caso de las mujeres y otras realidades de género, la situación se agrava dado el imperio del patriarcado como política de dominación. 
Hablar de igualdades establecidas al amparo de derechos humanos ya es ocultar que la violencia sobre las mujeres sigue operando y hasta con mayor intensidad. Estas igualdades son un espejismo.

En ese "como si" desdibuja el acceso al pleno ejercicio de derechos. Es común leer resoluciones judiciales en los que se desvirtúan situaciones de clara violencia de género basadas en el presupuesto de que son existentes condiciones de igualdad que no existen. Desde allí es el mismo Estado el que perpetra violencias y desigualdades. Desde un marco legislativo tenemos que ser conscientes de la necesidad de una operatividad facilitadora de justicia e igualdad, y desde las responsabilidades de caben al Estado como agente promotor y garantista de derechos, tenemos que ir a la responsabilidad Estatal en caso de acciones u omisiones que violen derechos fundamentales de las personas.

Para ello es necesario volver a las responsabilidades de los agentes que ejecutan decisiones en el ámbito estatal. Hablamos de jueces, de legisladores, funcionarios de la administración pública. Es necesario promover sumarios, juicios políticos y todo tipo de procesos que cuestiones el accionar de las responsabilidades individuales en ejercicio del poder estatal.

En Argentina no existe un cuerpo legislativo nacional para tratar la violencia de género, las leyes regulatorias y sus procedimientos se establecen de acuerdo a la política de cada provincia o gobierno, y este tema sí debe ser abordado por una constitución Nacional. Los derechos de género y su operatividad deben quedar enmarcados en una nueva constitución de género. Una constitución debe forjarse en la inclusión social.

\section{Instituciones, derecho y género}

En estas dos últimas décadas, a través del compromiso y del trabajo de abogadas en el ámbito nacional, promotoras de 
la generación de un feminismo jurídico, inspiradas en feminismos, tanto estadounidense como latinoamericano, se han producido modificaciones tanto en la legislación como en el ámbito de la justicia local.

Las críticas al carácter androcéntrico del derecho, dieron lugar a la creación de una institucionalidad de género en la justicia, no sin que se deslice un carácter paradójico: las mismas prácticas que recogen denuncias son aquellas que por sus modalidades, por la precaria o ausente formación en temática de género de los operadores receptores de las denuncias y por otras cuestiones relativas a los procedimientos procesarles, estas prácticas suelen devenir violatorias de derechos, por lo tanto, desde lo institucional se vuelve a vulnerar a la víctima.

El derecho, y en particular, los criterios normativos que lo rigen implican la valoración objetiva y subjetiva de una conducta, planteando un borde entre lo que es socialmente aceptado y lo que excede esa aceptación. En función de ese umbral asigna responsabilidades y penas específicas de acuerdo con un criterio de valoración plasmado en una legislación codificada, en el caso específico del derecho argentino.

Desde una pretendida neutralidad quedan por fuera aspectos estructurales que afectan las relaciones sociales y asignan a sujetas y sujetos distintos posicionamientos que hacen a una desigualdad jurídica, entre otras desigualdades sociales.

Cuando hablamos de género, hablamos de una categoría social, de una construcción que supone acuerdos explícitos o tácitos dentro de un grupo social y momento histórico determinado. Este acuerdo está incrustado en la cultura de modo que atraviesa transversalmente a toda una sociedad, estereotipando sus conductas. La perspectiva de género comprende el abordaje de estos fenómenos sociales y ha desarrollado herramientas específicas tendientes a visibilizar, cuestionar, analizar, y diseñar políticas públicas, para crear políticas públicas para lograr una paridad social. 
Como ya dijimos, el campo de la justicia no es la excepción y las lógicas sociales y culturales conforman un parámetro con el que se estipulan conductas razonables, esperadas, conductas normalizadas. Las decisiones de los magistrados, en cuanto a la conducta esperable y a considerar conductas delictivas, por acción u omisión de aquello que era lo esperable, no tienen en cuenta, en muchas oportunidades, aquello que escapa por estar invisibilizado, que es la desigualdad estructural establecida por razones de género.

Los nuevos marcos institucionales no se han instalado sin conflictos y tensiones, incluso teniendo en cuenta una postura Estatal resistente a la conservación de un statu quo. Son actores sectoriales especializados los que han logrado, a través de la negociación, el alojamiento y tratamiento de intereses diversos.

A partir de la recuperación de la democracia, también comenzó a haber un marco más propicio para la formulación de otros reclamos y la creación de espacios en pos de visibilizar y reclamar derechos igualitarios.

Desde esta perspectiva, tanto el espacio público como el espacio privado fueron problematizados y han sido intervenidos con leyes específicas basadas y reguladas por nuevas legislaciones internacionales tendientes a erradicar la violencia de género y toda forma de discriminación: la Convención sobre la eliminación de todas las formas de discriminación contra la mujer (CEDAW) (1) y su Protocolo facultativo (1979), Convención Interamericana para Prevenir, Sancionar y Erradicar la Violencia contra la Mujer "Convención de Belem do Para" (2), que propone el desarrollo de mecanismos de protección y defensa de los derechos de las mujeres como fundamentales para luchar contra el fenómeno de la violencia contra su integridad física, sexual y psicológica, tanto en el ámbito público como en el privado y su reivindicación dentro de la sociedad y también legislación impulsada por movimientos de mujeres y feministas, y también, desde los últimos años, colectivos LGBTI y colectivos por la diversidad sexual. 
La finalidad de los marcos normativos internacionales y de sus programas específicos, consiste en establecer un marco regulatorio y reparador de desigualdades provenientes de políticas públicas que como estas son un reflejo directo de un orden establecido; y solucionar injusticias producidas basadas en estas desigualdades.

En Argentina, en el año 2009, se sanciona la Ley 26.485, Ley de protección integral para prevenir, sancionar y erradicar la violencia contra las mujeres en los ámbitos en que desarrollen sus relaciones interpersonales. Esta Ley surge con el apoyo del Consejo Nacional de las Mujeres, y a través de un proceso de participación y reflexión, involucrando sectores de la sociedad civil y de áreas involucradas en esta Ley. Este trabajo se realizó para comprender la trascendencia de la problemática de las violencias contra las mujeres.

El objetivo de esta legislación ha pretendido plasmarse en la creación de oficinas específicas para la atención de reclamos de mujeres u oficinas de atención especializadas en diversidad sexual; también se adoptaron medidas de afirmación positiva como la inclusión de mujeres en cargos públicos; y también se generaron políticas y se diseñaron planes para la transversalización del género en la institución estatal, políticas y medidas que aún están en su fase inicial de desarrollo y que evidencian problemáticas propias de una etapa de evidencia experimental, sin criterios claros en el diseño de programas de transversalización. En este sentido, se han realizado experiencias de cursos de perspectiva de género en oficinas públicas y no hay acuerdo sobre si esos cursos deben ser obligatorios o no. Las opiniones que avalan la opcionalidad de los mismos se fundan en la idea de que pueden generar posiciones reactivas y efectos contraproducentes. Otras experiencias, han arrojado efectos positivos ante la imposición de la realización de jornadas de perspectiva de género obligatorias. Todavía no hay una estadística clara que permita investigar el impacto de este tipo de políticas. 


\section{Soberanía, Género y Constitución. Hacia dónde vamos}

¿Cómo pensar Soberanía, Género y Constitución? Tres palabras, que están escindidas de la realidad en la que vivimos, en los marcos institucionales, en un Estado que por sus prácticas y sus omisiones viola derechos bumanos fundamentales de las mujeres, de las diversidades de género.

Pensar hoy en la soberanía desde un espacio de género nos coloca en el lugar de resignificar este concepto para transformar el régimen héteropatriarcal, productor de desigualdades necesarias para su conservación.

Esta transformación no será posible si no vamos a las normas y entre ellas a la carta fundamental de un estado, la Constitución Nacional.

Hacia una soberanía de género

Sabemos que lo personal es político. Este saber lo llevamos inscripto en el cuerpo. La politización de la vida no es otra cosa que la comprensión de la vulnerabilidad propia y las ganas de establecer los nuevos umbrales de la dignidad colectiva.

El héteropatriarcado es una forma de vida, un sistema cultural, y cómo tal ha disciplinado nuestros deseos, anhelos, aspiraciones, ha disciplinado nuestros cuerpos.

Por lo tanto, no solo hay que resistir en pos de reivindicarnos como sujetas autónomas y soberanas, tenemos que exigir normas de convivencia que garanticen nuestros derechos, una norma fundamental que sea lo suficientemente sólida como para crear un estado sustentable en igualdad y justicia. Una norma que garantice nuestras libertades individuales y colectivas.

Sabemos que una justicia que no es de género no es justicia, una Constitución que es arrasada día a día por las prácticas de una ley no inscripta, que es la ley patriarcal, no es efectiva, y toda norma que cae en desuso es arrasada.

Con respecto a la legalidad desde aspectos simbólicos, no queremos que la norma sea arrasada, porque si la ley declina, 
surgen otros ordenamientos, esos que son abusivos, esos que constituyen la fuerza subterránea que hoy promueve los femicidios, avalados por estados feminicidas, las violaciones, la condena social hacia las mujeres, hacia las diversidades sexuales, los padres abusivos (y es tan vigente recordar a ese padre de la horda patriarcal en estos tiempos dónde la ley está flojita), la violencia de género, los excesos y abusos de la justicia con las mujeres en los juzgados de familia, los malos tratos institucionales hacia las mujeres que denuncian, hacia las mujeres que van a parir, hacia las mujeres que trabajan en mercados negros, hacia las mujeres acosadas, que permiten la trata, la explotación, los femicidios continuos e invisibilizados de compañeras travestis, la explotación sexual infantil de niñas, de torturas y deshumanización de las compañeras privadas de libertad en la cárcel, el derecho restringido es el de la libertad, no todos los demás derechos produciendo deshumanización y derrumbamiento subjetivo). Y así podría seguir lo que queda de la jornada porque hay algo que se desprende que es evidente, inocultable, algo por lo que estamos acá reunidos: sin derechos humanos, sin derechos fundamentales garantizados no existe estado de derecho. Sin una constitución de género, no hay justicia social.

¿Cómo entonces no pensar en la necesidad de una nueva constitución, una constitución de género?

El derecho a la vida, tan puesto en cuestión en el último año en relación al aborto, en reclamo de las soberanías del cuerpo, aborto, tenemos que considerar, en defensa del derecho a la vida que por mueren miles de mujeres y niñas por año por prácticas de abortos clandestinos y que muchas niñas y mujeres son obligadas a ser madres en situaciones luego de ser violadas.

La apuesta radical por la vida no consiste en reivindicar la Vida en mayúsculas sino en tomar una posición en torno a los límites de la vida digna.

Defendiendo el derecho a la vida impulsamos regulaciones especiales para detener los femicidios, debemos demandar 
respuestas y accionares concretos al Estado, a través d sus funcionarios y jueces, para que este no sea un Estado Feminicida

Es un buen punto de partida, generar leyes que protejan la vida digna de todas y todos, y esto supondrá también subvertir los valores y la racionalidad del sistema patriarcal y para eso, necesitamos empezar con una Constitución fuerte e inclusiva.

Por lo tanto, la propuesta transformadora tiene que construirse desde la vida cotidiana. Por eso son necesarios los saberes de esas cotidianeidades para legislar realidades y no imaginarios disciplinantes. Esta propuesta pasa por reapropiarnos de las soberanías desde los aprendizajes de género, para así poder construir la Soberanía de Género. Una soberanía que hay que poner en marcha más allá o, mejor dicho, más acá de los Estados. La soberanía hay que pelearla desde la vida misma.

En este sentido, la soberanía es un proceso individual y colectivo. El concepto de soberanía parte desde el propio cuerpo, parte de las libertades económicas, por la equiparación de recursos en tanto que las mujeres solemos ser asignadas también a tareas no remuneradas que debilitan nuestros espacios decisorios. Sabemos que la incorporación de la mujer al ámbito laboral remunerado ha implicado una doble carga de trabajo para las mujeres, quienes seguimos cuidando a nuestros hijos y otros familiares, mientras trabajamos para obtener ingresos, mayoritariamente, en empleos precarios. Contamos con condiciones laborales peores que las de sus compañeros recibiendo una remuneración económica inferior por las mismas tareas y teniendo que trabajar más tiempo para percibir los mismos ingresos. Sabemos que en los mercados laborales estamos en clara desventaja, no solo porque llevamos la ocupación de la mayoría del cupo laboral en negro, o porque ganamos menos (entre el 27 y el 40 por ciento) sino porque también trabajamos en forma no remunerada en las economías familiares que sostienen al varón privilegiado en su desarrollo laboral, económico y profesional. 
El acceso al campo laboral remunerado es un derecho de todas y todos que debe estar enmarcado en el Cuerpo de una nueva constitución. El reconocimiento del trabajo a través de la remuneración está ligado al reconocimiento de la dignidad humana.

Y desde allí en adelante, porque para ser soberanas hoy necesitamos tener las capacidades, los recursos (materiales, afectivos y relacionales) y las instituciones sociales que nos permiten construir las vidas que queremos vivir.

Para ser soberanas hoy, necesitamos tener el poder de movilizar y decidir sobre los recursos o elementos que son indispensables para la reproducción de la vida. Esto implica que necesitamos cuestionar y reinventar las instituciones sociales mediante las cuales organizamos y sostenemos nuestras vidas.

En este sentido, la soberanía de género implica democratización política, ya que significa que las sujetas somos sujetas políticas y protagonistas del cambio de nuestras vidas. Por eso estamos trabajando hacia nuestro empoderamiento, para el ejercicio del poder reconocido, para ser voces, con cupos igualitarios en instituciones, los partidos, los sindicatos y los movimientos sociales.

Superar la lógica productivista, garantizar el reconocimiento y el reparto colectivo de los trabajos domésticos y de cuidados, así como garantizar los ingresos igualitarios y la remuneración de tareas hasta ahora no remuneradas, para superar así la división sexual del trabajo, superar los modelos actuales de familia, amistad y de sexualidad, y revolucionar los modelos hegemónicos de identidad sexual, son imperativos que demás está por decir, necesitan el amparo de una nueva constitución.

\section{VIII. ¿Por qué una Constitución de Género?}

Una Constitución de género debería regirse por el principio de paridad democrática en todos los procesos y órganos decisorios; que se constitucionalice un derecho a la educación en 
la diversidad, de carácter no sexista: la educación tendría que orientarse a formar identidades masculinas y femeninas que superasen los lastres del patriarcado: la mística de la feminidad en el ámbito privado y los procesos de masculinización en el espacio público.

Necesitamos una Constitución garantice el derecho a una vida libre de violencias machistas; violencias con las que no ha logrado acabar nuestras leyes de la Ciudad Autónoma de buenos Aires, ni las leyes provinciales (porque es curioso que además no haya una ley nacional, entonces las provincias, al amparo de los posicionamientos feudo patriarcales reinantes regulan a su albedrio). Entonces, cabe insistir: proteger nuestros derechos en el nivel infraconstuticional es abiertamente insuficiente.

Los derechos sexuales y reproductivos deberían contemplarse constitucionalmente. El derecho a la interrupción voluntaria del embarazo, será Ley.

Queremos una Constitución de Género que asuma que nuestros cuerpos son también la última frontera en la conformación y la deconstrucción de nuestras identidades, de manera que, cuando hablamos de derechos sexuales y reproductivos, hemos de hablar también de interseccionalidad y transfeminismo.

Una Constitución feminista que regule derechos para evitar la interiorización del locus reproductivo y de cuidados, la marginación de quienes se ocupan del sostenimiento de la vida y de quienes depende, en buena parte, nuestro sistema productivo, incorporando el derecho al cuidado y el derecho a la conciliación de la vida personal, familiar y laboral como proyección del libre desarrollo de la personalidad.

Necesitamos una Constitución de Género que garantice el derecho a los consumos vitales básicos de luz, agua y gas, que deberían ser definidos y gestionados como bienes comunes; debería poner en marcha políticas públicas de mayor impacto comunitario, recuperar el control público de los servicios esenciales para garantizar el derecho a la subsistencia 
(vivienda, agua, energía, sanidad), y limitar, por todos los medios, la concentración de la riqueza y la especulación de los grandes oligopolios.

Queremos una Constitución que garantice el derecho de las personas al acceso a la justicia, pero el efectivo acceso a la justicia y no un mercado elitista de acceso que se define por la capacidad de invertir mayores recursos, como sabemos que pasa. Queremos una justicia dinámica, una justicia justa que expuse a jueces injustos, que cumpla con el cupo igualitario y se acceda a sus cargos por voto popular, como ocurre con los otros dos poderes) ¿por qué la justicia es el único poder al que no se accede por el voto democrático?

Queremos una justicia de género, no queremos una justicia feminicida,

Sabemos que la Constitución en su artículo 75, inciso 22, integra tratados internacionales, y esto, no significa de modo alguno que estos sean complementarios y accesorios de la parte dogmática de la Constitución Nacional, sino que integran el plexo de valores, irradian principios y postulan mandatos normativos de orden público de la misma manera que el texto constitucional vernáculo reconociera desde los albores de su institucionalidad a la fecha.

Integrar es ser parte de, y por ello, dice el mandato, "tienen jerarquía” con lo que ubica en grado de paridad con la parte dogmática, siendo las expresiones subsiguientes explicativas de tal prescripción indudable.

Releyendo la Convención sobre la Eliminación de toda forma de Discriminación contra la Mujer (CEDAW, ONU), o al leer la Convención Interamericana para prevenir, sancionar y erradicar la violencia contra la mujer (Convención de Belem do Para, OEA), es posible observar con claridad que este estado no garantiza casi ningún derecho allí establecido.

Dice el art. 4 que Toda mujer tiene derecho al reconocimiento, goce, ejercicio y protección de todos los derechos humanos y a las libertades consagradas por los 
instrumentos regionales e internacionales sobre derechos humanos. Estos derechos comprenden, entre otros:

a. el derecho a que se respete su vida;

b. el derecho a que se respete su integridad física, psíquica y moral;

c. el derecho a la libertad y a la seguridad personales;

d. el derecho a no ser sometida a torturas;

e. el derecho a que se respete la dignidad inherente a su persona y que se proteja a su familia;

f. el derecho a igualdad de protección ante la ley y de la ley;

g. el derecho a un recurso sencillo y rápido ante los tribunales competentes, que la ampare contra actos que violen sus derechos;

h. el derecho a libertad de asociación;

i. el derecho a la libertad de profesar la religión y las creencias propias dentro de la ley, y

j. el derecho a tener igualdad de acceso a las funciones públicas de su país y a participar en los asuntos públicos, incluyendo la toma de decisiones.

Los derechos fundamentales quedan en el nivel enunciativo si no tenemos leyes programáticas, leyes que reglamenten su ejercicio y obligatoriedad, leyes que operen como garantía de los mismos y esa obligatoriedad hacia el Estado debe quedar claramente escrita en una Nueva Constitución de Género.

Sabemos que, ante las lagunas legislativas, los poderes de turno y el presente poder patriarcal rellena huecos con sus propias normas disciplinantes.

Sabemos que los estados violan derechos y garantías por omisión. Pero esas operaciones no son azarosas ni dependen siquiera del poder de turno en su totalidad, es la norma patriarcal la que rige imperativamente en pos del disciplinamiento de lo femenino en pos de su dominación y explotación. Por eso, cuando hablamos de garantías, estas no pueden ser planteadas en términos de abstracción. Un estado tiene un rol activo como 
garante de la soberanía individual y colectiva de las mujeres. En su rol activo debe sancionar a quienes violen los derechos de las sujetas.

Si retomamos el espíritu de la Constitución del 49, y tomamos conciencia de la necesidad de una constitución que introduzca modificaciones sustanciales amparando derechos sociales, necesitamos una Nueva Constitución de Género.

No queremos más una constitución de hombre y para hombres, queremos una constitución para todas las personas. 